\title{
One year outcome of percutaneous tracheostomy in severe head injury
}

Martino C. ${ }^{1}$, Russo E. ${ }^{1}$, Di Prospero S. ${ }^{2}$, Bilotta F. ${ }^{3}$, Agnoletti V. ${ }^{1}$, Chieregato A. ${ }^{4}$

${ }^{1}$ AUSL Romagna - Ospedale Maurizio Bufalini, Surgery and Trauma, Cesena, Italy, ${ }^{2}$ Ospedale Sant'Andrea- Sapienza, Università di Roma, Dept of Anaesthesiology \& Intensive Care, Rome, Italy, ${ }^{3}$ Policlinico Umberto I, Dept of Anaesthesiology, Rome, Italy, ${ }^{4}$ Ospedale Niguarda, Dept of Anaesthesiology \& Intensive Care, Milan, Italy

Background: In the setting of neurocritical care, percutaneuos tracheostomy technique(PDT) indications and advantages are recognized; early tracheostomy decreases both pulmonary morbidity and critical care resource utilization.Conversely to early complications, the late outcome of PDT is less studied.

The aim of the study was to verify prospectically the rate of late complications in a cohort of patients submitted to one year outcome evaluation after severe traumatic brain injury (TBI) and who underwent PDT in the acute phase.

Materials and Methods: 247 TBI patients tracheostomized in the acute phase were evaluated after 1 year.All tracheostomies were performed in the ICU using the Ciaglia Percutaneous Tracheostomy Set with endoscopic guide.

At one year follow up disability was quantified by means of the extended Glasgow Outcome Scale and PDT outcome was focused on symptom interview and the physician examination with the cutaneous scar assessment.After this initial screening the patients symptoms severity were was summarized according their relevance in pauci symptomatic ( 1 symptom minimally significant), clearly symptomatic ( 2 or more symptoms presents or only one major intensity or need of surgical or medical treatment).

Results and Discussion: Tab 1 describes patients characteristics.

Tab 2 shows the late PDTcomplication rate.

The overall rate and the severity of complications seems to be associated with poorer neurological outcome and this correlation is significative (Fig 1) Time of cannulation is longer in patients with poorer recovery (Fig.2).

Table 1: Patient characteristics $(\mathrm{N}=247)$

\begin{tabular}{|l|l|l|}
\hline & & \\
\hline Age (years) & $42.48(19.47)$ & Mean (SD) \\
\hline Male & $44(70.96)$ & $\mathrm{N}(\%)$ \\
\hline Apache chronic A & $54(87)$ & $\mathrm{N}(\%)$ \\
\hline Apache chronic B & $6(13)$ & $\mathrm{N}(\%)$ \\
\hline mGCS ad NSH admission & $3.5(3)$ & Median (IQR) \\
\hline ISS & $27(14.5)$ & Median (IQR) \\
\hline Length of tracheal intubation (days) & $3(2)$ & Median (IQR) \\
\hline
\end{tabular}

mGCS; motor component of Glasgow Coma Scale score; ISS. Injury Severity Score; $\mathrm{NSH}$, neurosurgical hospital

Tab 2: Late complication rate at one year follow up $(\mathrm{N}=247)$

\begin{tabular}{|c|c|c|}
\hline & & $\mathrm{N}(\%)$ \\
\hline Scar assessment & $\begin{array}{ll} & \text { Retraction } \\
- & \text { Cheloid } \\
\text { - } & \text { Tracheo-cutaneous fistula }\end{array}$ & \begin{tabular}{|l}
$44(18)$ \\
$9(4)$ \\
$5(2)$
\end{tabular} \\
\hline Dyspnea & & $2(0.8)$ \\
\hline Dysphonia (minimal) & & $20(8)$ \\
\hline Cough & $\begin{array}{ll}- & \text { Minimal } \\
- & \text { Severe }\end{array}$ & \begin{tabular}{|l|}
$9(3.6)$ \\
$1(0.4)$
\end{tabular} \\
\hline Stridor & & $3(1.2)$ \\
\hline Disfagia (minimal) & & $39(15.8)$ \\
\hline $\begin{array}{l}\text { Surgical therapy for } \\
\text { complications }\end{array}$ & $\begin{array}{ll}- & \text { Tarcheo-cutaneous fistula } \\
\text { - } & \text { Tracheal stenosis }\end{array}$ & $\begin{array}{l}4(1.6) \\
3(1.2)\end{array}$ \\
\hline
\end{tabular}

Fig.1 Rate of tracheostomy related symptoms and neurological outcome $(\mathrm{p}=0.0081)$

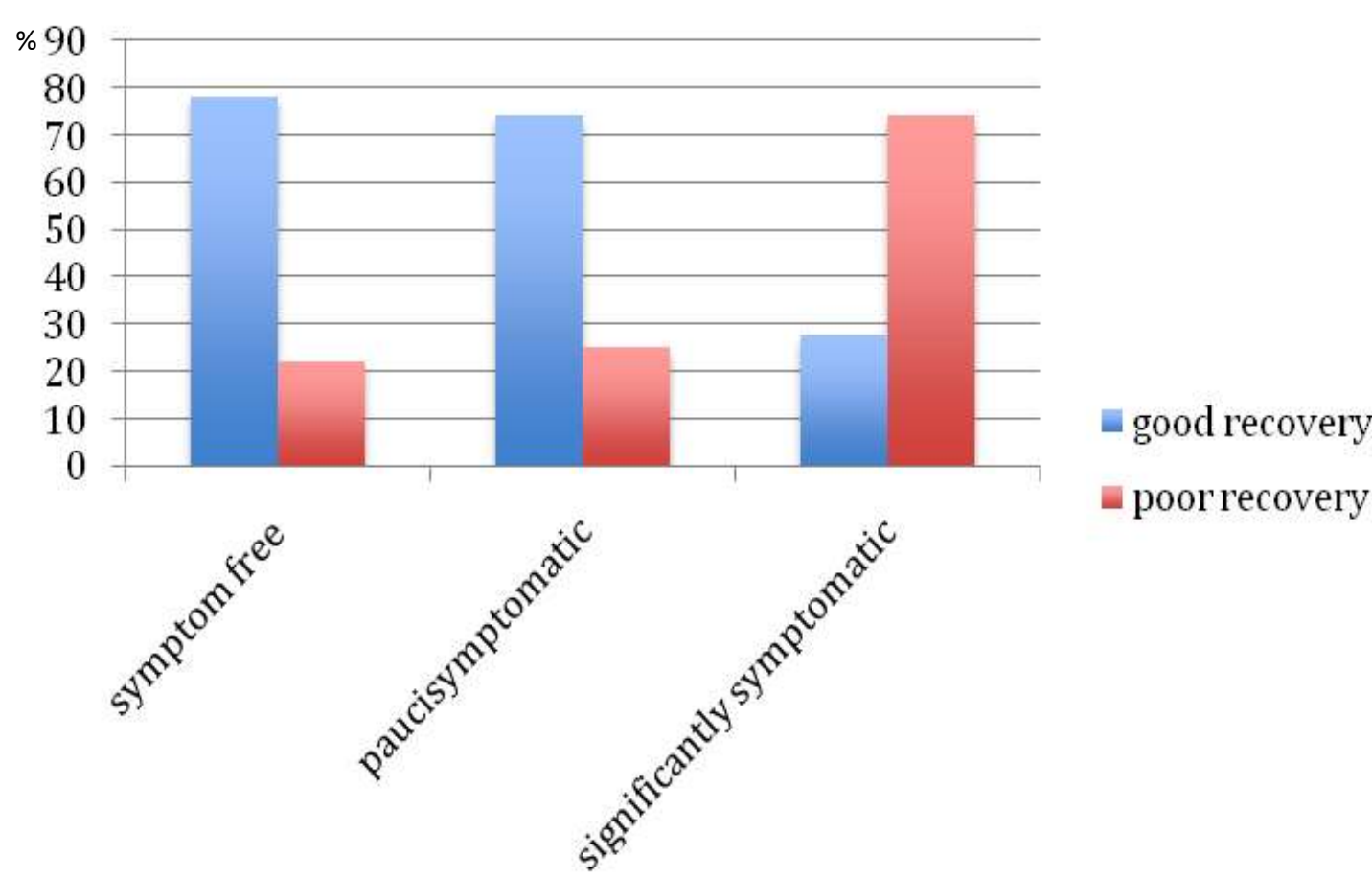

Fig.2 Mean time of cannulation and neurological outcome $(\mathrm{p}<0.001)$

60

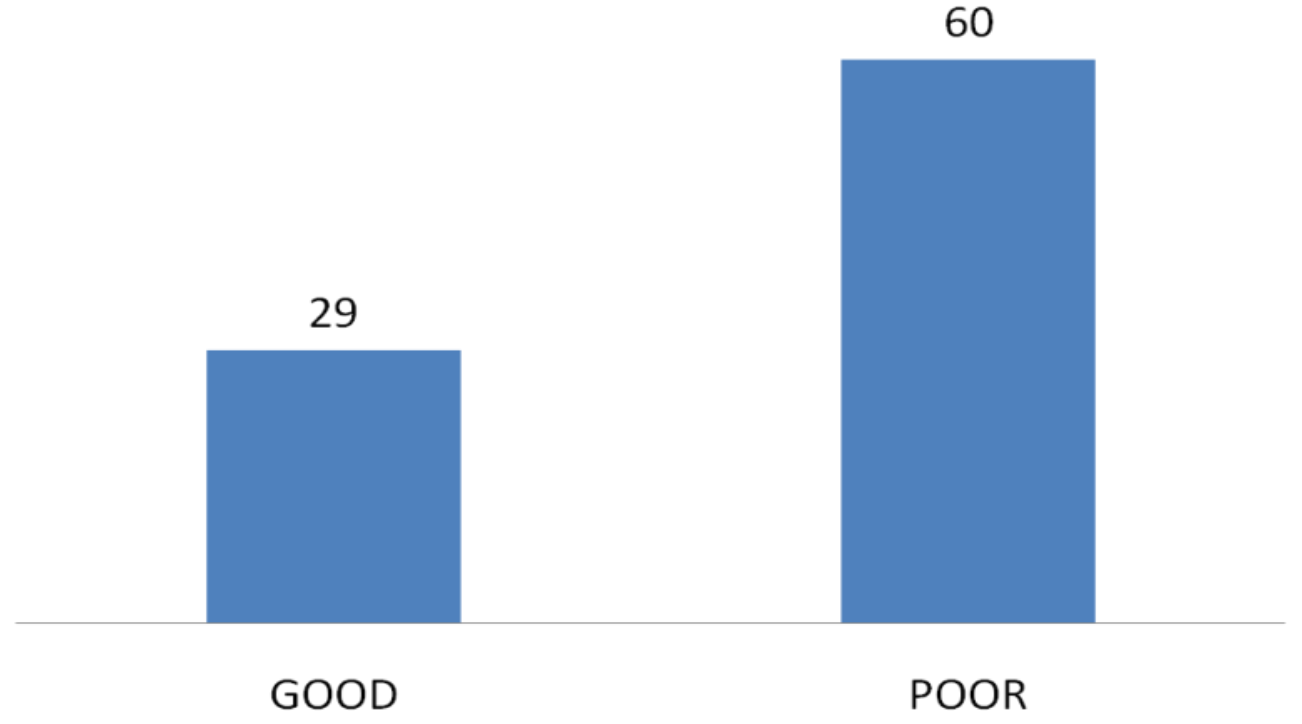

-Median days : 30(IQR 22.5)

\section{Conclusion}

Late symptomatic complications seem to be associated with unfavourable neurological outcome. The longer time of cannulation in patients with poor neurological outcome is a factor known to be associated to delayed complications.

The worst initial damage, more secondary insults, prolonged and more aggressive medical therapies may prolong ventilation and may be associated more frequently with infection. Primary damage of cranial mixed nerve related or brainstem dysfunction may be associated with prolonged dysfunction of swallowing reflex. Overall this findings may be associated with a prolonged time of cannulation in patients with poorer recovery. 